EESTI NSV TEADUSTE AKADEEMIA TOIMETISED, 22, KOIDE KEEMIA * GEOLOOGIA. 1973, NR. 2

ИЗВЕСТИЯ АКАДЕМИИ НАУК ЭСТОНСКОИ ССР. ТОМ 22 ХИМИЯ * ГЕОЛОГИЯ. 1973, № 2

\title{
КИНЕТИКА ДИСПРОПОРЦИОНИРОВАНИЯ ЭТИЛБЕНЗОЛА И ИЗОМЕРИЗАЦИЯ ДИЭТИЛБЕНЗОЛА
}

В кислотном катализе с участием фенилалканов протекает реакция диспропорционирования, которая во многих случаях определяет состав конечных продуктов синтеза:

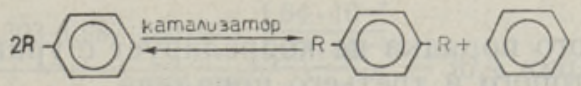

Особое значение эта реакция имеет в промышленных синтезах алкилирования бензола алкенами, переалкилирования диалкилбензолов, получения алкилфенилэтиловых спиртов и т. д. Удельное значение реакций диспропорционирования алкильных групп в отдельных процессах зависит от рода и качества кислотного катализатора, температуры реакции и начальной концентрации реагирующих веществ, длины цепи и строения алкильного радикала. В реакциях алкилирования бензола алкенами или переалкилирования диалкилбензолов эта реакция протекает при избытке бензола и порядок ее различен по отношению к отдельным компонентам $\left[{ }^{1,2}\right]$.

В данной работе эта реакция рассматривается в условиях, соответствующих синтезу алкилфенилэтиловых спиртов:

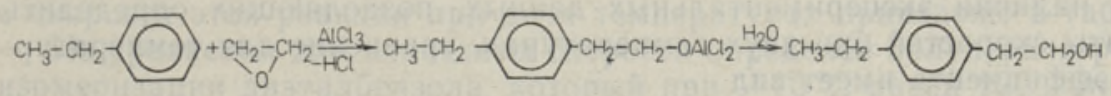

т. е. при относительно низких температурах и большом избытке хлористого алюминия (1-3 моля на моль этилбензола). Методика синтеза и хроматографического анализа продуктов приведены в сообщении [3].

Для получения кинетических характеристик этой реакции проводятся специальные опыты. В реактор загружается этилбензол, охлаждается до $-10^{\circ} \mathrm{C}$ и при энергичном перемешивании прибавляется хлористый алюминий в молярном соотношении $3: 1$. Через каждые 15 мин отбирается проба и быстро выливается на лед для торможения реакции. После отбора пятой пробы температура поднимается до $0^{\circ} \mathrm{C}$ и последовательно отбирается еще 5 проб и т. д. Последняя проба отбирается при комнатной температуре и 16-часовой выдержке.

Все вычисления сделаны на основе газохроматографического анализа отдельных проб и характеризуют состав продуктов и исходных веществ, соответствующих данной температуре реакции. 
Данные о скорости реакции диспропорционирования этилбензола при температурах $0^{\circ}$ и $-10^{\circ} \mathrm{C}$ приведены в табл. 1 .

Из данных табл. 1 следует, что диспропорционирование этилбензола является мономолекулярной реакцией первого порядка. Константа ско-

Таблица 1

Скорость реакции диспропорционирования этилбенззла

\begin{tabular}{|c|c|c|c|c|c|}
\hline \multicolumn{3}{|c|}{ При $-10^{\circ} \mathrm{C}$} & \multicolumn{3}{|c|}{ При $0^{\circ} \mathrm{C}$} \\
\hline $\begin{array}{l}\text { Время от- } \\
\text { бора проб, } \\
\text { мин }\end{array}$ & $\begin{array}{r}\text { Отношение } \\
C_{0} / C, \text { моль \% }\end{array}$ & $\begin{array}{c}\text { Константа } \\
\text { скорости, } \\
k_{1} \cdot 10^{-3}, \text { мuн }^{-1}\end{array}$ & $\begin{array}{l}\text { Время от- } \\
\text { бора проб, } \\
\text { мин }\end{array}$ & $\begin{array}{r}\text { Отношение } \\
C_{0} / C, \text { моль \% }\end{array}$ & $\begin{array}{c}\text { Константа } \\
\text { скорости, } \\
k_{2} \cdot 10^{-2}, \text { мuн }^{-1}\end{array}$ \\
\hline 0 & 1,000 & - & 0 & 1,000 & - \\
\hline 15 & 1,019 & $1, \overline{23}$ & 15 & 1,267 & $1, \overline{58}$ \\
\hline 30 & 1,039 & 1,27 & 30 & 1,660 & 1,64 \\
\hline 45 & 1,060 & 1,29 & 45 & 2,055 & 1,60 \\
\hline 60 & 1,081 & 1,29 & 60 & 2,695 & 1,66 \\
\hline Cpe: & 68,8 & 1,27 & & 68,8 & 1,64 \\
\hline
\end{tabular}

рости реакции первого порядка не коррелирует с уравнением константы скорости реакции второго и третьего порядков.

Изменение логарифмов концентрации во времени носит линейный характер. Из уравнения для константы скорости определен полупериод реакции диспропорционирования этилбензола, который при $-10^{\circ} \mathrm{C}$ составляет 546 мин, а при $0^{\circ} \mathrm{C}-42,3$ мин, причем полупериод не зависит от исходной концентрации, что также указывает на первый порядок реакции.

Энергия активации $E$ была вычислена на основании уравнения Аррениуса

$$
\lg k=\lg k^{\prime}-\frac{E}{2,303 \cdot R T}
$$

или, переходя к натуральным логарифмам,

$$
k=k^{\prime} e^{-E / R T} \text {. }
$$

При наличии экспериментальных данных, позволяющих определить константы скоростей при двух температурах, уравнение для температурного коэффициента имеет вид

$$
\frac{k_{4}}{k_{1}}=e^{\frac{E}{R} \cdot \frac{T_{2}-T_{1}}{T_{2} \cdot T_{1}}}
$$

и для энергии активации

$$
E=\frac{2,303 R T_{1} \cdot T_{2} \cdot \lg \frac{k_{2}}{k_{1}}}{T_{2}-T_{1}},
$$

где $R$ - универсальная газовая постоянная, равная $1,987 \kappa a л / 2 р а д$. - 2-моль;

$T_{1}$ и $T_{2}$ - температура реакции в ${ }^{\circ} \mathrm{K}$;

$k_{1}$ и $k_{2}$ - константы скорости реакции при температурах $T_{1}$ и $T_{2}$.

Энергия активации реакции диспропорционирования этилбензола по уравнению (6) составляет 
Таблица 2

Диспропорционирование этилбензола и изомерный состав диэтилбензола

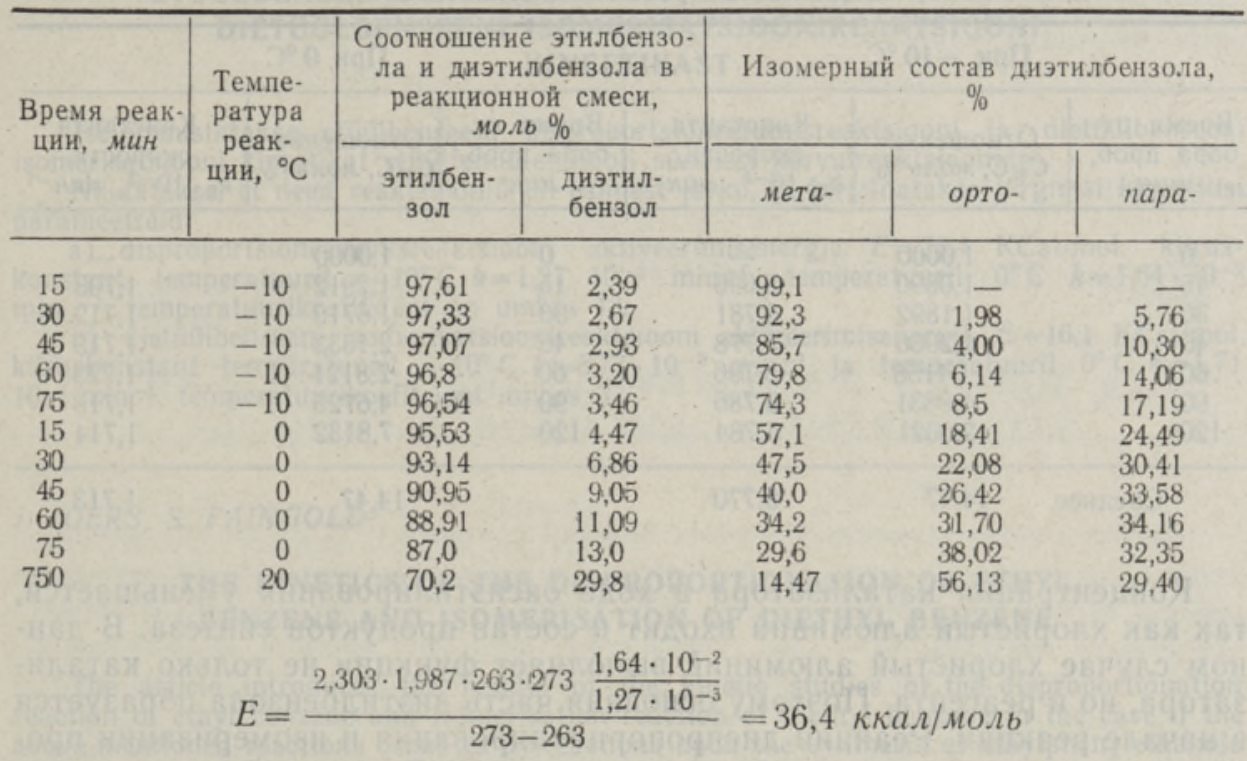

и температурный коэффициент скорости этой реакции по-Вант-Гоффу равен приблизительно 13.

Такой высокий температурный коэффициент объясняется, по-видимому, большим количеством применяемого хлористого алюминия $(1-3$ моля на моль этилбензола). С увеличением температуры возрастают растворимость хлористого алюминия в этилбензоле и количество катализируемого комплекса хлористого алюминия с этилбензолом.

При диспропорционировании этилбензола вначале образуется метадиэтилбензол, который изомеризуется в орто- и пара-изомеры (табл. 2) . Энергетически наиболее устойчивым является орто-изомер, поскольку содержание его в смеси при состоянии равновесия наибольшее - $56,13 \%$. Суммарная скорость образования пара- и орто-изомеров равна скорости изомеризации мета-изомера.

Реакция изомеризации диэтилбензола имеет первый порядок. Данные о скорости этой реакции при двух температурах приведены в табл. 3.

Из уравнения для константы скорости определен полупериод реакции изомеризации диэтилбензола, который при $-10^{\circ} \mathrm{C}$ равен 120 мин, а при $0^{\circ} \mathrm{C}-40,6$ мин.

Энергия активации реакции изомеризации диэтилбензола по уравнению (6) составляет

$$
E=\frac{2,303 \cdot 1,987 \cdot 263 \cdot 273 \frac{1,713 \cdot 10^{-2}}{5,770 \cdot 10^{-3}}}{273-263}=16,1 \text { ккаль } / \text { моль }
$$

и температурный коэффициент скорости этой реакции равен

$$
\frac{k_{t}+10}{k_{t}}=\frac{1,713 \cdot 10^{-2}}{5,770 \cdot 10^{-3}}=2,96 .
$$

В данном случае температурный коэффициент подчиняется правилу Вант-Гоффа, хотя применяемое количество катализатора сравнительно больше, чем в обычных реакциях алкилирования. 
Скорость изомеризации диэтилбензола

\begin{tabular}{|c|c|c|c|c|c|}
\hline \multicolumn{3}{|c|}{ При $-10^{\circ} \mathrm{C}$} & \multicolumn{3}{|c|}{ При $0^{\circ} \mathrm{C}$} \\
\hline $\begin{array}{l}\text { Время от- } \\
\text { бора проб, } \\
\text { мин }\end{array}$ & $\begin{array}{c}\text { Отношение } \\
C_{0} / C, \text { моль } \%\end{array}$ & $\begin{array}{c}\text { Константа } \\
\text { скорости, } \\
k_{1} \cdot 10^{-3}, \text { мин }^{-1}\end{array}$ & $\begin{array}{c}\text { Время от- } \\
\text { бора- проб, } \\
\text { мин }\end{array}$ & $\begin{array}{c}\text { Отношение } \\
C_{0} / C, \text { моль \% }\end{array}$ & $\begin{array}{c}\text { Константа } \\
\text { скорости, } \\
k_{2} \cdot 10^{-2}, \text { мuн }^{-1}\end{array}$ \\
\hline $\begin{array}{r}0 \\
15 \\
30 \\
45 \\
60 \\
90 \\
120\end{array}$ & $\begin{array}{l}1,0000 \\
1,0890 \\
1,1892 \\
1,2966 \\
1,4158 \\
1,6831 \\
2,0021\end{array}$ & $\begin{array}{l}\overline{-} \overline{696} \\
5,781 \\
5,778 \\
5,796 \\
5,786 \\
5,784\end{array}$ & $\begin{array}{r}0 \\
15 \\
30 \\
45 \\
60 \\
90 \\
120\end{array}$ & $\begin{array}{l}1,0000 \\
1,2912 \\
1,6710 \\
2,1633 \\
2,8121 \\
4,6725 \\
7,8132\end{array}$ & $\begin{array}{l}\overline{1} \overline{703} \\
1,712 \\
1,715 \\
1,723 \\
1,713 \\
1,714\end{array}$ \\
\hline Средн & 14,47 & 5,770 & & 14,47 & 1,713 \\
\hline
\end{tabular}

Концентрация катализатора в ходе оксиэтилирования уменьшается, так как хлористый алюминий входит в состав продуктов синтеза. В данном случае хлористый алюминий выполняет функции не только катализатора, но и реагента. Поэтому основная часть диэтилбензола образуется в начале реакции. Реакции диспропорционирования и изомеризации протекают в основном в первой стадии синтеза. В дальнейшем роль их уменьшается и к концу процесса становится вовсе незначительной.

\section{Выводы}

1. Определены кинетические показатели побочных реакций диспропорционирования этилбензола и изомеризации диэтилбензола, сопровождающих основную реакцию присоединения окиси этилена к этилбензолу при получении этилфенилэтилового спирта.

2. Диспропорционирование этилбензола при избытке хлористого алюминия является реакцией первого порядка; константа скорости при $-10^{\circ} \mathrm{C}$ равна $1,27 \cdot 10^{-3}$ мин $^{-1}$ и при $0^{\circ} \mathrm{C} 1,64 \cdot 10^{-2}$ мин $^{-1}$, энергия акти. вации составляет 36,4 ккал/моль; температурный коэффициент равен приблизительно 13.

3. Изомеризация диэтилбензола при избытке хлористого алюминия является реакцией первого порядка; константа скорости при $-10^{\circ} \mathrm{C}$ составляет $5,77 \cdot 10^{-3}$ мин $^{-1}$, а при $0^{\circ} \mathrm{C} 1,713 \cdot 10^{-2}$ мин $^{-1}$; энергия активации равна 16,1 ккал/моль; температурный коэффициент - приблизительно 3.

\section{ЛИ ТЕ Р А Т У Р А}

1. Л е бедев Н. Н., О р е ши н М. М., Нефтехимия, 7, № 1, 26 (1967).

2. Л еб еде в Н. Н., О ре ши и М. М., Нефтехимия, 7, № 2, 199 (1967).

3. Ф а йн гольд С. И., И ы е р Я. Х., Синтез этилфенилэтиловых спиртов, В сб. статей III Всес. совещ. по синтезу и терминологии ПАВ, Таллин, 1972. 


\section{J. JOERS, S. FAINGOLD}

\section{ETUULBENSEENI DISPROPORTSIONEERUMISREAKTSIOONI JA DIETUULBENSEENI ISOMERISATSIOONIREAKTSIOONI KINEETIKAST}

Iseloomustatakse etüülbenseeni disproportsioneerumisreaktsiooni ja dietüülbenseeni isomerisatsiooni kineetikat etüülfenüületanooli sünteesi kõrvalreaktsioonides.

Näidatakse, et need reaktsioonid on esimest järku, ja kirjeldatakse järgmisi kineetilisi parameetreid:

a) disproportsioneerumisreaktsiooni aktiveerimisenergia $E=36,4 \mathrm{KCal} / \mathrm{mol}$, kiiruskonstant temperatuuril $-10^{\circ} \mathrm{C} k=1,27 \cdot 10^{-3} \mathrm{~min}^{-1}$, temperatuuril $0^{\circ} \mathrm{C} k=1,64 \cdot 10^{-2}$ min ${ }^{-1}$, temperatuurikoefitsient on umbes 13 ;

b) dietüülbenseeni isomerisatsioonireaktsiooni aktiveerimisenergia $E=16,1 \mathrm{KCal} / \mathrm{mol}$, kiruskonstant temperatuuril $-10^{\circ} \mathrm{C} k=5,77 \cdot 10^{-3} \min ^{-1}$ ja temperatuuril $0^{\circ} \mathrm{C} k=1,71$ $10^{-1} \mathrm{~min}^{-1}$, temperatuurikoefitsient umbes 3 .

\section{J. JOERS, S. FAINGOLD}

\section{THE KINETICS OF THE DISPROPORTIONATION OF ETHYL BENZENE AND ISOMERISATION OF DIETHYL BENZENE}

The article introduces the results of the kinetic studies of the disproportionation reaction of ethyl benzene and isomerisation reaction of diethyl benzene in the case if the above-mentioned reactions occur as by-reactions upon the synthesis of ethylphenylethanols in the presence of aluminium chloride.

The reactions under the examination are reactions of the first order. The activation energy of disproportionation is $36.4 \mathrm{KCal} / \mathrm{mol}$, and of the reaction of isomerisation $16.1 \mathrm{KCal} / \mathrm{mol}$.

The speed constant of the reaction of isomerisation at the temperature of $-10^{\circ} \mathrm{C}$ is $5.77 \cdot 10^{-3} \mathrm{~min}^{-1}$, and at $0^{\circ} \mathrm{C}$ it is $1.71 \cdot 10^{-1} \mathrm{~min}^{-1}$.

The temperature coefficient for the reaction of disproportionation is 13 , and 3 for the reaction of isomerisation. 